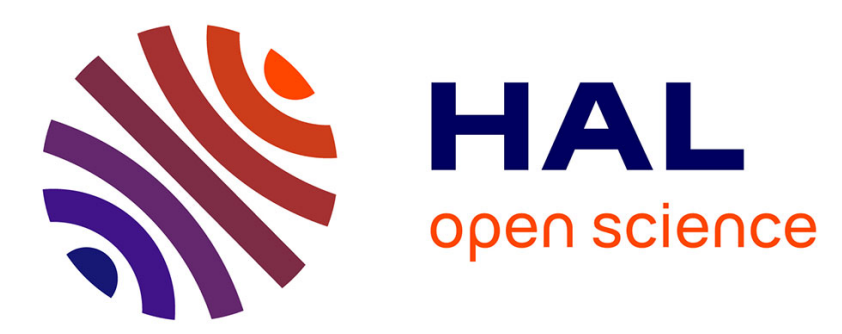

\title{
A PRELIMINARY STUDY ON THE INFLUENCE OF ROOM ACOUSTICS ON PIANO PERFORMANCE
}

\author{
S. Bolzinger, J. Risset
}

\section{To cite this version:}

S. Bolzinger, J. Risset. A PRELIMINARY STUDY ON THE INFLUENCE OF ROOM ACOUSTICS ON PIANO PERFORMANCE. Journal de Physique IV Proceedings, 1992, 02 (C1), pp.C1-93-C1-96. 10.1051/jp4:1992116 . jpa-00251119

\section{HAL Id: jpa-00251119 https://hal.science/jpa-00251119}

Submitted on 1 Jan 1992

HAL is a multi-disciplinary open access archive for the deposit and dissemination of scientific research documents, whether they are published or not. The documents may come from teaching and research institutions in France or abroad, or from public or private research centers.
L'archive ouverte pluridisciplinaire HAL, est destinée au dépôt et à la diffusion de documents scientifiques de niveau recherche, publiés ou non, émanant des établissements d'enseignement et de recherche français ou étrangers, des laboratoires publics ou privés. 


\title{
A PRELIMINARY STUDY ON THE INFLUENCE OF ROOM ACOUSTICS ON PIANO PERFORMANCE
}

\author{
S. BOLZINGER and J.C. RISSET \\ Laboratoire de Mécanique et d'Acoustique, C.N.R.S. - L.M.A., 31 chemin Joseph Aiguier, \\ F-13402 Marseille cedex 09, France
}

\begin{abstract}
This is a preliminary study trying to describe the influence of room acoustics on piano performance. Professional pianists were asked to play the same piece in different acoustic conditions. Objective data on musical events were obtained, thanks to the Yamaha Disklavier, an acoustic piano with MIDI input and output. A statistical analysis, updated in real time, has yielded numeric results describing each performance. A preliminary analysis of the differences induced by changes in the acoustics shows which aspects of the performance are affected, and establishes the sensitivity of the produced sound intensity to the acoustic absorption in the room. Further analysis gives more details and allow to propose a model for the phenomenon.
\end{abstract}

\section{The experiment}

Our experiment was made possible by the availability of the following equipment : the acoustic and MIDI piano Yamaha Disklavier, a computer station for real-time analysis of MIDI messages, and a room with variable acoustics.

The piano Yamaha Disklavier had a double function : first to be exactly similar to a normal upright piano, so that the pianist can play as he is used to; and also to be equiped with MIDI measuring devices, which gives in real time the MIDI codes of the performance played. Theses codes (note or pedal number, hammer's velocity) are captured directly on the piano mechanism and then coded according to the MIDI standard.

The real-time analysis station is a Macintosh IIx computer, connected to a MIDI interface (Opcode Studio Plus Two), and equipped with the MAX software, written by Miller Puckette at IRCAM and distributed by Opcode Systems. This software is an object-oriented programming environment for realtime signal processing, and especially for MIDI. In our case it is used to perform real-time analysis of the piano perfomance, through an objective parsing of the MIDI events. Thanks to MAX we can have numerical results of the analysis immediatly after each performance.

In order to analyse the influence of room acoustics on the performance, it is necessary to isolate the variable "acoustics" from the other variables that can affect the performance : the visual environment, in particular, should be exactly the same for the pianist, in the different acoustics, so that he or she may stay unaware of the changes. A room with variable acoustics was obtained by the following transformations : the most reverberant acoustics is the empty room, the least reverberant one is the same room with absorbing panels covering the walls and the floor. Intermediate acoustics is obtained by partially covering these surfaces. In front of the piano, a paper curtain hides the panels so that the pianist cannot see anything, but still hears the acoustic response of the room, as the acoustic absorption by stretched paper is insignificant. In this changeable room, it is possible to make the subject play in several differents acoustics on the same day, which lets him have the best reproductibility in his performances. 
Four different acoustics were selected : two extreme and two intermediate ones. In the four cases, the reverberation time was calculated from the measure of the level decay of a wide-band noise, filtered through a normal octave band (central frequencies ranging from $125 \mathrm{~Hz}$ to $4 \mathrm{kHz}$ ). Typically, at 1000 Hertz the reverberation times were 0,3 and 1,5 seconds for the extreme cases, and 0,7 and 1 second for the intermediate ones. It was found that the extreme cases were considered as musically very bad, and the two others could be considered comparable to a concert situation.

The experiment was organised as follows : the pianists knew neither what the purpose of the measures would be, nor that changes would be made in the acoustic environment. They were asked to repeat five times the same performance, with a reproductibility as good as possible. Two recordings were made in the same acoustic condition, in order to estimate this reproductibility. Before each recording the pianists had a training period of a few minutes.

With this experimentation system 16 musical excerpts of various styles (from Bach to Debussy) were recorded by five pianists. Four of them were professionnal concert players. Each pianist played different sections selected in his own repertory.

\section{Real-time performance analysis}

An analysis of musical performance was performed to ascertain the influence of acoustics. It is not a study of musicality, but a statistical analysis of parameters which are calculated in the same way for all the performances (i.e. without taking the score in account). It consists of correctly parsing the MIDI information, calculating the differents parameters of the timing of events (durations, overlaps...), and compiling their statistical analysis. It was implemented in the MAX software, with the graphical object programmation.

The first task of the analysis is to give acoustic significance to the information. As the MIDI message is composed of note-ons, note-offs, pedal-ons or offs, and velocity values, it has to be parsed to get a real meaning. The acoustic relevance of each code is considered, and the pairs on/off for each note are put together, in real time and from any MIDI messages flow. This parsing is necessary for further real-time calculation.

Timing data then make possible the calculation of the duration and the overlap of each note, in milliseconds. According to the sequential order of the MIDI events, each note is detected as either detached or slurred. The overlap value is then calculated either as a staccato value, or as a legato value. The other parameters for statistical analysis are : MIDI velocity, accents frequency (detected by velocity peak), velocity contrast, instantaneous tempo, silence durations and pedal timing.

The wide possibilities of MAX object programming are used for the statistical analysis, which gives averages, cumulated sums, counts and histograms for 15 parameters in real time. At the end of a recording, 15 histograms and 25 numerical results are stored and ready for comparison.

\section{Preliminary analysis results}

Although some parameters, such as the contrast, the accentuation, and the use of the soft pedal, do not seem to be affected by the changes in the acoustics, other parameters appear to vary with those changes. In almost all cases, we found that the midi velocity, the silence duration, the staccato proportion, the use of the sustain pedal, and the average tempo, change according to the acoustics changes. When the reverberation time increases, we observe that the pianists play softer (the midi velocity decreases), more detached (the staccato proportion and the silence duration increase), a little slower (the tempo decreases), and with less sustain pedal, although they try to play exactly the same way. Part of these results can be seen in figures 1 and 2.

The five pianists share these same trends, with some personal differences (one of them has played with an almost constant tempo). The non-professional one has also accomplished non-significant changes, since his variance in playing the same excerpt in the same condition was as large as the changes. One of the professionals did know the purpose of the experiment, so that he was more aware of the reverberation (without knowing in which setting of the room he was playing) : he accomplished the same changes than the others, but in a larger proportion.

We then observed that all these above parameters, except the average tempo, are directly correlated to the sound intensity produced. As the change in reverberation relates to these changes, we can assume that they serve a purpose of compensating the changes in the room acoustics. To check this hypothesis, further analysis is necessary. 


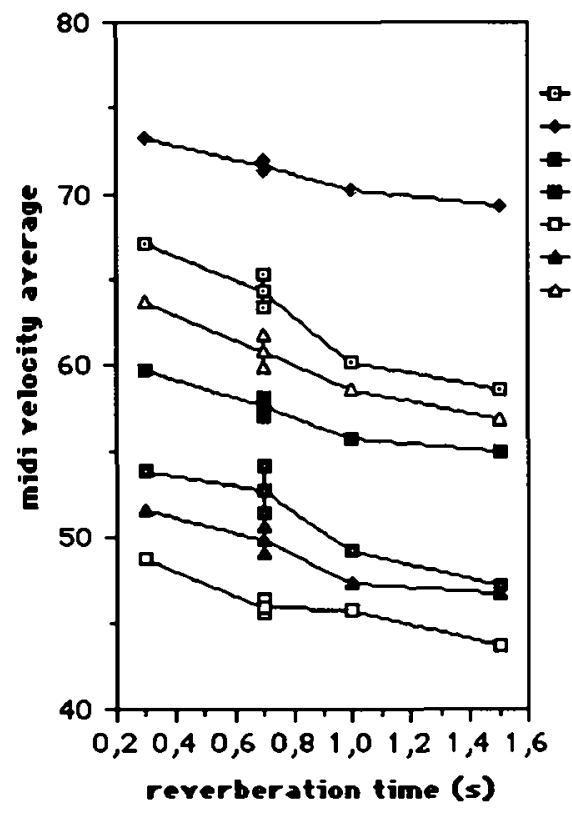

FIGURE $t$

Midi velocity average changes

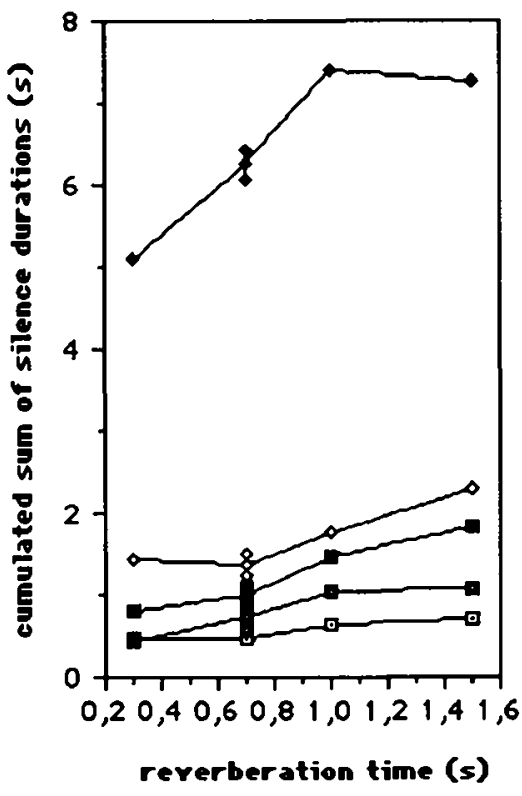

FIGURE 2

Changes in the cumulated sum of silence durations

\section{Further analysis results}

The preliminary results demonstrate the existence of an influence of room acoustics on the performance, as described. We are still elaborating this description, by performing more refined analysis using sound intensity measurements and re-play of excerpts of the same performances.

Knowing the correspondance between midi velocity and sound intensity is important to understand the phenomenon. The midi velocity depends upon the velocity of the hammer. Clearly, the larger the velocity, the louder the sound. But it is worth investigating the correspondance between the midi velocity and the acoustic level produced. A measurement performed close to the strings with the B\&K 2209 sonometer gives the correspondance curve. From these values, we can calculate in real time the sound intensity produced by the pianist. We observe that the average level produced decreases when reverberation increases. However, we can say that the average level heard in the room increases with the reverberation, because the reflections produce an increase in the acoustic level of about $9 \mathrm{~dB}$ between the two extreme conditions, whereas the decrease in the sound intensity produced by the pianist's performance is about $3 \mathrm{~dB}$. Hence the pianist heard his own performance with a loudness difference of $6 \mathrm{~dB}$ between the two extreme situations. Our preliminary hypothesis on the compensation of the loudness decrease due to change in the room acoustics remains plausible, but it is only a partial compensation.

The analysis of excerpts of performances is also interesting to understand what happens. The MIDI recording gives a corpus of performance data which can be submitted to score analysis : as all the preliminary results were obtained without considering the score, an extraction of specific notes of the score can give new indications about the influence of the acoustics. For example, the inspection of level curves (measured and plot by B\&K equipment) indicates that the level of the leading melodic line is less affected by the acoustics changes than the level of the other notes. This could come from either the separation of melody and accompaniment in the pianist's perception, or from differences of reverberation time for low or high frequencies. Further investigations are in progress, using a MAX extraction program making it possible to replay only selected subsets of the recorded performances (the Yamaha Disklavier is also capable of receiving MIDI messages and performing the corresponding music by moving keys and pedals). 


\section{v Phenomenon modelisation}

To conclude, the influence of acoustics changes on piano performance can be decribed by the model proposed in figure 3 , which assumes an uncounscious feedback on sound intensity, in the sense that the pianist, although he tries not to, does change his performance by trying to hear the same thing in different acoustic conditions. This experiment establishes the importance of this auditory feedback on the performance, in particular its influence on the sound intensity. At the same time it suggests that the compensation of the change of level due to room acoustics is not complete. The feedback from hearing the more or less reverberated sound is not the only possible one : for example one can speculate that the feeling of muscular action gives a kinesthesic feedback, which depends upon the piano mechanism. There may also be muscular and technical limitations of the dynamics of the performance. Some pianists had a different feeling of their own touch in different acoustics : when they played in the most absorbant room, they indicated that either their fingers or the piano mechanism seemed to be in a different condition. In any case, the experiment results suggest a more careful control of the acoustics of piano practice rooms.

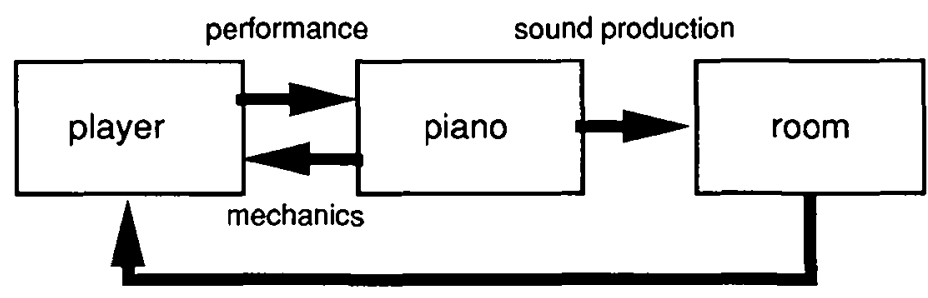

reverberation

FIGURE 3

Phenomenon modelisation :

Uncounscious feedback on sound intensity

\section{References}

BOLZINGER, S. (1991) ; "Etude préliminaire de l'influence de l'acoustique de la salle sur le jeu du pianiste" ; Rencontres scientifiques du cinquantenaire du L.M.A. : Colloque Genèse et perception des sons ; Publications L.M.A. $n^{\circ} 128,115-117$

PALMER, C. (1989) ; "Timing in skilled music performance" ; Doctorate in Philosophy, Cornell University, U.S.A.

ROSS, J. (1989) ; "A study of timing in an Eustonian runic song" ; J. Acoust. Soc. America ; 86 (5), $1671-1677$

PALMER, C. (1989) ; "Mapping musical thought to musical performance" ; J. Exp. Psychology : Human perception and performance ; vol.15, $n^{\circ} 12,331-346$

PRESSING, J. (1987) ; "The micro- and macrostructural design fo improvised music"' ; Music perception; vol.5, N²,133-172

Acknowledgements to YAMAHA for the lending of the Disklavier piano model MX100A. 